\title{
Montelukast use over the past 20 years: monitoring of its effects and safety issues
}

Yong Ju Lee, $\mathrm{MD}^{1}$, Chang-Keun Kim, $\mathrm{MD}^{2}$

${ }^{1}$ Department of Pediatrics, Yongin Severance Hospital, Yonsei University College of Medicine, Yongin, Korea; ${ }^{2}$ Asthma and Allergy Center, Department of Pediatrics, Inje University Sanggye Paik Hospital, Seoul, Korea

Montelukast, a leukotriene receptor antagonist, was launched 20 years ago in Korea. It is recommended as an alternative treatment for asthma in children with mild persistent symptoms or as an add-on treatment to existing low-dose inhaled corticosteroids (ICSs) in children who require additional treatment. However, in the real-world setting, many doctors and patients prefer montelukast over ICSs despite their lower efficacy. Although montelukast is considered to be a safe drug, there are concerns regarding adverse drug reactions, including the rare occurrence of Churg-Strauss syndrome and, despite insufficient data, the possibility of neuropsychiatric events such as anxiety, depression, sleep disturbance, and suicidality. This review identified that montelukast has significantly contributed to asthma control over the past 20 years in Korea and has been critical for reducing asthma severity, especially early wheezing and disease control. Our findings suggest that the effects of montelukast treatment can be monitored by measuring serum eosinophilderived neurotoxin levels.

Key words: Respiratory sounds, Asthma, Montelukast, Child, Eosinophil-derived neurotoxin

\section{Key message}

Although the efficacy of montelukast is inferior to that of ICS, both physicians and parents prefer montelukast to ICSs.

EDN may be a useful biomarker for the treatment and monitoring of preschool children with asthma.

The US FDA requires boxed warning about serious neuropsychiatric events of montelukast, therefore, physicians should consider the benefits and risks of montelukast before prescribing it.

\section{Introduction}

Leukotrienes (LTS) are substances secreted by leukocytes that have three conjugated double bonds. Researchers have known since 1930 that the sputum of asthmatic patients contains a sub- stance that causes smooth muscle constriction. ${ }^{1)}$ This substance was termed slow-reacting substance of anaphylaxis (SRS-A) since it causes slow contractions of the smooth muscle after being released from sensitized lungs during an anaphylactic reaction. ${ }^{2)}$ In the late 1970s, SRS-A was shown to be part of the LT family. ${ }^{3)}$ In 1980, the LTs C4 and D4 (LTC4 and LTD4, respectively) reportedly showed remarkable contractile activity on isolated human bronchi. ${ }^{4}{ }^{4}$ Thereafter, the number of studies on LTs as candidate asthma treatments increased. LT modifiers include LT receptor antagonists (LTRAs) and 5-lipoxygenase (5-LO) inhibitors. LTRAs include zafirlukast, montelukast, and pranlukast, while 5-LO inhibitors include zileuton. Of these, montelukast is the most widely prescribed and studied worldwide. This review describes the synthesis and function of LTs and the effects and safety of montelukast, a representative LTRA.

\section{Biosynthesis of LTs}

The biosynthesis of LTs begins in the cell membrane. When a variety of biological stimuli occur, phospholipids in the cell membrane are metabolized to arachidonic acid (AA) by phospholipase A2. AA is converted to prostaglandin (PG) or thromboxane by cyclooxygenase or to 5 -hydroperoxyeicosatetraenoic acid (5-HPETE) by 5-LO and 5-LO-activating protein (FLAP). Next, 5-HPETE is transformed into 5-hydroxyeicosatetraenoic acid (5-HETE) or LTA4. LTA4 is then converted to LTB4 by LTA4 hydrolase or binds to reduced glutathione using LTC4 synthase to form LTC4. LTC4 is converted to LTD4 by the removal of glutamic acid by $\alpha$-glutamyl transpeptidase, while LTD4 is converted to LTE4 by the removal of glycine by dipeptidase. LTC4, LTD4, and LTE4 are called cysteinyl LTs (cysLTs) because they contain cysteine.

\section{Role of LTs in the airway}

CysLTs have several effects that contribute to the pathogenesis

Corresponding author: Chang-Keun Kim, MD. Asthma and Allergy Center, Department of Pediatrics, Inje University Sanggye Paik Hospital, 1342 Dongil-ro, Nowon-gu, Seoul 01757, Korea 
of asthma. First, they act as potent bronchoconstrictors in humans. When the lung tissues of asthmatic patients were stimulated with specific allergens, cysLT secretions increased and the cysLT amounts released were correlated with bronchial smooth muscle contractions. ${ }^{5)}$ When LTD4 was inhaled in vivo, the bronchial smooth muscle contracted and lung function was decreased regardless of asthma status. ${ }^{6}$ CysLTs up-regulate the expression of endothelial adhesion molecules, act as a powerful chemoattractant for eosinophils, and reduce eosinophil apoptosis, thus leading to eosinophilic inflammation. ${ }^{7)}$ CysLTs also increase vascular leakage, which in turn exacerbates mucosal ede$\mathrm{ma}$, increases mucus production and secretion by goblet cells, and decreases mucociliary clearance. ${ }^{8-10)}$ Furthermore, cysLTs contribute to airway remodeling, promote smooth muscle cell proliferation, and increase collagen deposition in the airways (Fig. 1). 11,12)

CysLT receptors are classified as cysLT1 and cysLT2. Montelukast, zafirlukast, and pranlukast are selective cysLT1 antagonists. CysLT1 is expressed by macrophages, dendritic cells, eosinophils, basophils, mast cells, B cells, CD4+ T cells, hematopoietic progenitor cells, epithelial cells, airway smooth muscle cells, fibroblasts, fibrocytes, and endothelial cells. CysLT2 is expressed by macrophages, eosinophils, basophils, mast cells, epithelial cells, fibrocytes, and endothelial cells. ${ }^{13)}$ The binding affinity for cysLT1 among cysLTs is the highest in LTD4, followed by LTC4 and LTE, which shows very weak binding affinity. The binding affinity for cysLT2 is similar in LTD4 and LTC4, while that of LTE4 is weak. . $^{13-}$ 15) There is no currently available selective cysLT2 antagonist. Commercialized LTRAs, such as montelukast, pranlukast, and zafirlukast, act selectively on cysLT1 but not cysLT2. Therefore, asthma-associated cysLT activity is thought to involve cysLT1.

\section{Clinical use of montelukast in children with asthma}

\section{Current pediatric asthma management guidelines}

The current guidelines state that low-dose inhaled corticosteroids (ICS) may be used primarily in children of all ages when maintenance therapy is needed and that LTRAs should be administered as an alternative treatment. If step-up treatment is required, the prescription of moderate-dose ICS or LTRAs in combination with low-dose ICS is recommended for children aged $<6$ years. For children aged $\geq 6$ years, the use of low-dose

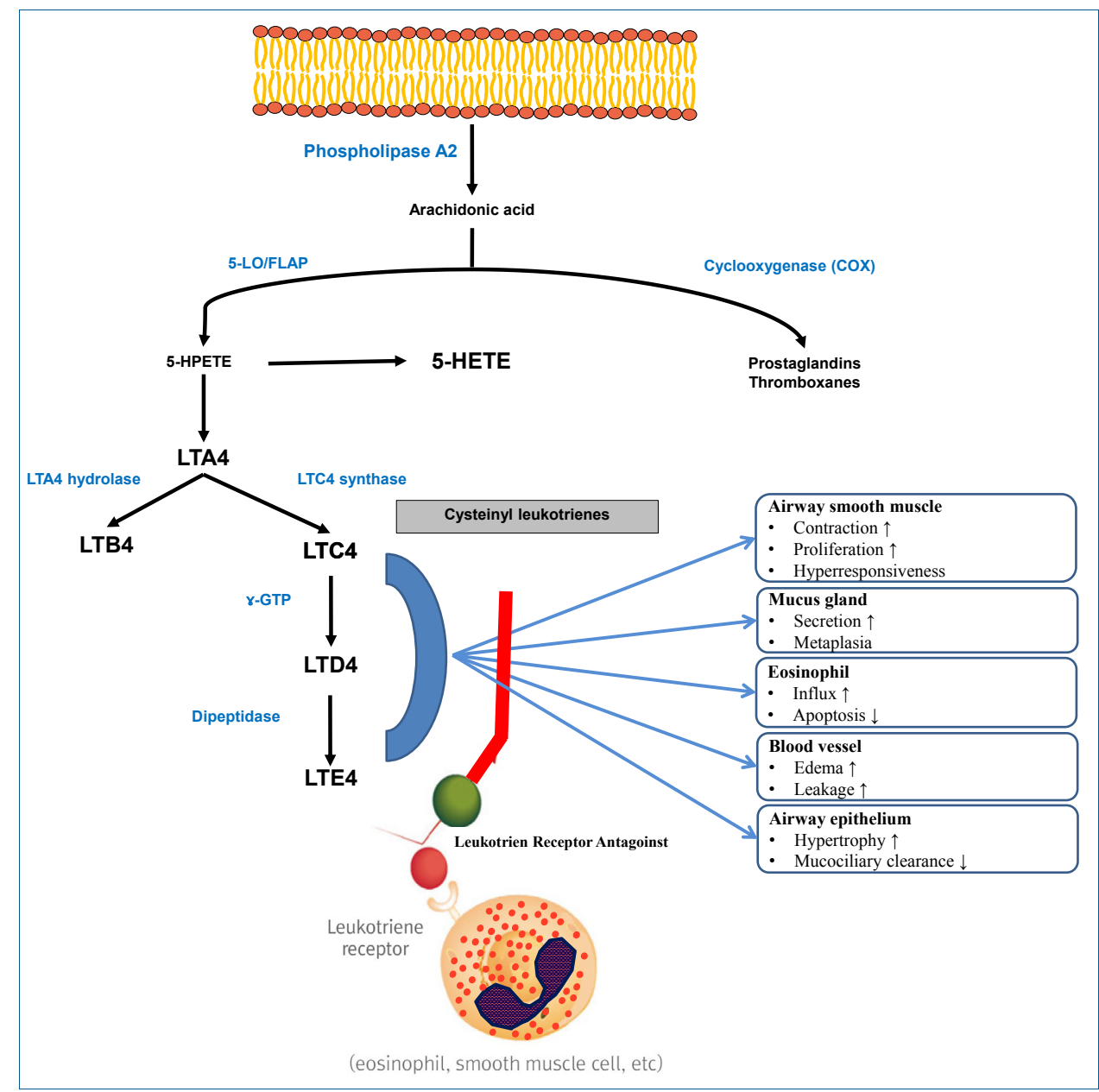

Fig. 1. Biosynthesis and role of leukotrienes. 5-LO, 5-lipoxygenase; FLAP, 5-LO-activating protein; 5-HPETE, 5-hydroperoxyeicosatetraenoic acid; 5-HETE, 5-hydroxyeicosatetraenoic acid; LT, leukotriene; GTP, glutamyl transpeptidase. 
ICS in combination with long-acting beta-2 agonists is recommended, while high- or low-dose ICS with LTRAs are recommended as alternative treatments. ${ }^{16,17)}$

\section{Comparison with ICSs}

A Cochrane review that analyzed 19 pediatric randomized controlled trials (RCTs) to compare the efficacy of montelukast to that of ICS revealed the superior efficacy of the latter. ${ }^{18)} \mathrm{A}$ meta-analysis of RCTs in preschoolers with asthma or recurrent wheezing also reported that daily ICS use was more effective than montelukast treatment. ${ }^{19)}$ However, several studies showed different outcomes in real-life environments since the actual effects of a medication are determined by both medication efficacy and patient compliance. Ducharme et al..$^{20)}$ examined the real-life effectiveness of montelukast versus ICS in children with mild or moderate asthma. Physicians prescribed medication for $62 \%$ of the follow-up period when prescribing ICS versus $97 \%$ of followup when prescribing montelukast. Patients purchased $51 \%$ versus $74 \%$ of the prescribed ICS and montelukast at pharmacies, respectively. As a result, children who were prescribed ICS used the medication for $24 \%$ of the follow-up period, while those who were prescribed montelukast used the medication for $38 \%$ of the follow-up period. There was no intergroup difference in the rates of oral corticosteroid use or emergency room visits, but the ICS prescription groups were the more frequently admitted and more frequently required rescue beta- 2 agonists. ${ }^{20)}$ According to a study analyzing the Korean National Health Insurance claim database from 2010 to 2014, LTRAs including montelukast were the most prescribed in children of all ages with asthma. The rate of ICS prescriptions for asthmatic patients aged $\geq 6$ years was $<15 \% .{ }^{21}$ ) These results suggest that Korean pediatricians prefer to prescribe montelukast rather than ICS. In a recent survey of 1,838 pediatric patients currently receiving treatment for asthma in Korea and their parents, $38 \%$ of patients receiving inhaled treatment and $50 \%$ of those receiving LTRAs were taking the treatment as prescribed. Furthermore, $70 \%$ of LTRA users versus only $34 \%$ of inhaler users felt that their treatment modality was easy to use. ${ }^{22}$

A randomized study comparing responses to fluticasone inhaler and montelukast treatment in school-aged children with mild to moderate asthma defined a response as a $\geq 7.5 \%$ improvement in forced expiratory volume in 1 second $\left(\mathrm{FEV}_{1}\right)$, and showed that $5 \%$ of the children responded to montelukast only, $23 \%$ responded to fluticasone only, $17 \%$ responded to both medications, and 55\% responded to neither medication. Predictors of good response to fluticasone only were lower pulmonary function and provocative concentration causing a 20\% drop in $\mathrm{FEV}_{1}$, and higher FeNO levels, total eosinophil counts, serum eosinophil cationic protein (ECP), and total immunoglobulin E. Conversely, predictors of good response to montelukast were lower age and short duration of asthma. ${ }^{23)}$

In summary, although the efficacy of montelukast is inferior to that of ICSs and asthma management guidelines recommend that ICSs be prescribed primarily when starting maintenance therapy, both physicians and patients prefer montelukast to ICSs.
In addition, some patients respond better to montelukast than to ICS, but additional studies are needed to determine which patients will respond better.

\section{Preschool children with asthma or recurrent wheezing}

There are currently no specific tools or biomarkers available to diagnose asthma in preschool children. Therefore, it is important for physicians to recognize the various patterns of recurrent wheezing in this population. The proposed phenotypes of recurrent wheezing in early childhood are as follows: transient wheezing, nonatopic wheezing, persistent asthma, and severe intermittent wheezing. ${ }^{24,25)}$ This classification is helpful in understanding childhood wheezing but is difficult to use clinically. Wheezing may be classified as an "episodic (viral) wheeze" (EVW) or "multipletrigger wheeze" (MTW). ${ }^{26)}$ An EVW is defined as wheezing during discrete time periods, often in association with the clinical evidence of a viral cold, with an absence of wheezing between episodes. An MTW is defined as wheezing that shows discrete exacerbations but also symptoms between episodes.

A recent meta-analysis reported on the effects of montelukast treatment for the prevention of post-bronchiolitis wheezing. ${ }^{27)}$ The authors concluded that montelukast reduced the frequency of recurrent wheezing but did not reduce the incidence of recurrent wheezing, corticosteroid use, or number of symptom-free days in post-bronchiolitis infants; therefore, it was not appropriate for clinical use. However, in an RCT of post-bronchiolitis patients treated with montelukast for 3 months and followed up for 12 months, the serum eosinophil-derived neurotoxin (EDN) levels were significantly decreased and cumulative recurrent wheezing episodes were significantly decreased in the montelukast-treated group. ${ }^{28)}$

A Cochrane review of the effects of LTRA against EVW in preschool children reported that LTRA maintenance or intermittent therapy did not reduce the number of children experiencing one or more episodes requiring rescue medicine, emergency room visits, or hospital admissions. ${ }^{29,30)}$ However, the authors suggested that certain subgroups may respond to LTRA since children with EVW did not show homogeneous phenotypes and that they should be prescribed montelukast as a therapeutic trial and continue maintenance therapy if they respond well. The European Respiratory Society (ERS) recommended that, montelukast should be the first choice for daily maintenance therapy in children with EVW, while ICSs should be the first choice of maintenance therapy in children with MTW. However, the ERS highlighted that it is difficult to distinguish EVW from MTW in some children. ${ }^{31)}$ A recent meta-analysis of the effects of montelukast against both EVW and MTW in preschool children reported that montelukast was ineffective in preschool children with recurrent wheezing. The authors suggested that further studies should be conducted to investigate how to easily identify montelukast responders in clinical settings. ${ }^{32}$

EDN may be a useful biomarker for the treatment and monitoring of preschool children with asthma or recurrent wheezing. 33,34) $\mathrm{EDN}$ is one of four major proteins secreted by activated 
eosinophils together with ECP, major basic protein, and eosinophil peroxidase. Unlike the other three, EDN has an isoelectronic point of 8.3, which is close to neutral; therefore, it is possible to measure accurately and reproducibly in the blood. ${ }^{35)}$ In a previous study, we compared the concentrations of serum EDN to asthma symptom scores in preschool children. ${ }^{36}$ ) Serum EDN levels were the highest in children with acute asthma, followed by those with stable asthma and those in the control group, and the differences among the three groups were significant. Another study suggested that serum EDN levels 3 months after respiratory syncytial virus bronchiolitis were predictive of recurrent wheezing within 12 months. The serum EDN concentration cutoff value for predicting wheezing recurrence was $53 \mathrm{ng} / \mathrm{mL}$ (positive predictive value, $57 \%$; negative predictive value, $76 \%$; sensitivity, $72 \%$; and specificity, 62\%). The normal range of serum EDN concentration was $13-45 \mathrm{ng} / \mathrm{mL} .{ }^{28)}$ Predictive value of EDN levels for asthma was based on clinical performance result. Using $44.2 \mathrm{ng} / \mathrm{mL}$ (median+1SD) as the cut off for an elevated EDN level compared to those found in Controls, the sensitivity was $81.3 \%$, the specificity was $87.1 \%$, the positive predictive value (PPV) of EDN level for asthma $90.7 \%$, and the negative predictive value (NPV) was $75.0 \% .{ }^{35)}$ Another recent study compared the effects of montelukast and 0.5 -mg budesonide inhalation suspension therapy for 12 weeks in symptomatic preschool children with asthma and serum EDN levels $\geq 53 \mathrm{ng} / \mathrm{mL}$. ${ }^{37)}$ During the study period, asthma control days increased in both groups and there was no significant intergroup difference. However, serum EDN levels were significantly decreased only in the montelukast group. Therefore, based on several years of EDN-related research, we recommend starting maintenance therapy with montelukast when the EDN concentration is $\geq 53 \mathrm{ng} / \mathrm{mL}$ ( $1 \mathrm{SD}$ of normal) and stopping when it decreases to $<45 \mathrm{ng} / \mathrm{mL}$ (Fig. 2).

Current clinical practice guidelines recommended controller therapy for children experiencing daytime asthma symptoms more than once a week, with activity limitations, who require the use of a reliever more than once a week, or who have any nighttime symptoms. ${ }^{16}$ However, a recent study compared the

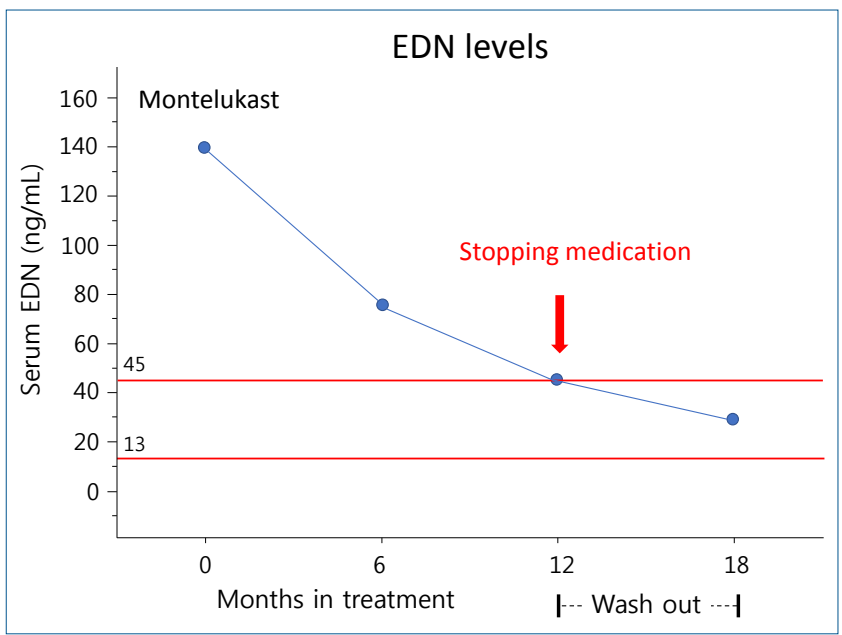

Fig. 2. Monitoring of leukotriene receptor antagonist effects. EDN, eosinophil-derived neurotoxin. efficacy of montelukast maintenance therapy and as-needed $\beta 2$ agonist therapy for 48 weeks in preschool children experiencing asthma symptoms more than once a month but less than once a week. ${ }^{38)}$ During the study, $28 \%$ of the montelukast group and $50 \%$ of the no-controller group experienced asthma exacerbations; $21 \%$ and $41 \%$ of the children, respectively, required increased treatment. Therefore, montelukast use should be considered as maintenance therapy in preschool children with intermittent asthma (Table 1).

The efficacy of LTRAs combined with antihistamines is often mentioned in clinical journals and guidelines. The combination of montelukast and 2nd-generation antihistamines may protect against seasonal decreases in lung function in patients with allergic rhinitis. Furthermore, LTRAs may be more effective at treating allergic rhinitis when combined with antihistamines since the agents have different efficacies. Recently, one such compound was developed and marketed for children in Korea. ${ }^{39}$

\section{Safety profile}

The most commonly reported clinical adverse events of montelukast treatment were fever, upper respiratory infection, and asthma exacerbation. However, montelukast is considered a safe drug because its reported incidence of adverse drug reactions (ADRs) was similar to that of the control group. ${ }^{40)}$

Major concerns related to montelukast-associated ADRs included the occurrence of Churg-Strauss syndrome (CSS) and the possible association between LTRA and suicidality. A casecrossover study of 78 patients with CSS reported that the use of montelukast was associated with a 4.5 -fold increased risk of CSS onset within 3 months. ${ }^{41)}$ CSS, also known as eosinophilic

Table 1. Clinical effects of montelukast in preschool children

\begin{tabular}{|c|c|}
\hline Phenotype & Clinical effects of montelukast \\
\hline \multicolumn{2}{|l|}{ Wheeze } \\
\hline $\begin{array}{l}\text { Episodic viral } \\
\text { wheeze }\end{array}$ & $\begin{array}{l}\text { Decrease in wheezing frequency after RSV } \\
\text { infection. No short-acting effects on reducing } \\
\text { wheezing episodes requiring rescue medicine, } \\
\text { ER visit, and hospital admission } \\
\text { Recommended as a therapeutic trial }\end{array}$ \\
\hline $\begin{array}{l}\text { Multiple-trigger } \\
\text { wheeze }\end{array}$ & $\begin{array}{l}\text { Montelukast responder' phenotype exists. } \\
\text { Studying how to easily identify these pheno- } \\
\text { types } \\
\text { Recommended as an alternative treatment of } \\
\text { low-dose ICS }\end{array}$ \\
\hline \multicolumn{2}{|l|}{ Asthma } \\
\hline Intermittent & $\begin{array}{l}\text { Effective on reducing asthma exacerbation } \\
\text { Recommended as an additional treatment of } \\
\text { short-acting beta agonist }\end{array}$ \\
\hline \multirow[t]{3}{*}{ Persistent } & $\begin{array}{l}\text { Effective on reducing serum EDN concentra- } \\
\text { tions. }\end{array}$ \\
\hline & $\begin{array}{l}\text { Less effective than daily ICS for improving asth- } \\
\text { ma symptoms and preventing exacerbation }\end{array}$ \\
\hline & $\begin{array}{l}\text { Recommended as an alternative treatment of } \\
\text { low-dose ICS }\end{array}$ \\
\hline
\end{tabular}

RSV. respiratory syncytial virus; ER, emergency room; ICS, inhalation corticosteroids; EDN, eosinophil-derived neurotoxin. 
granulomatosis with polyangiitis, is a rare autoimmune disorder that causes vasculitis in patients with a history of asthma or allergic rhinitis. Treatment for CSS includes glucocorticoids (such as prednisolone) and other immunosuppressive drugs. Therefore, montelukast is simply a confounding factor, and the withdrawal of steroid use may be associated with the development of CSS symptoms.

The United States Food and Drug Administration issued a warning in 2008 regarding the possible association between montelukast use and suicidality; moreover, in 2020, it announced that the drug requires a boxed warning about mental health side effects because many other antiallergy medicines can be prescribed instead and many health care professionals and patients/ caregivers are not aware of the risk of mental health side effects. Many studies that have analyzed published case reports or databases of adverse drug response reporting systems suggested that montelukast use is associated with neuropsychiatric events such as anxiety, sleep disturbance, depression, and suicidality. ${ }^{42-44)} \mathrm{A}$ recent nested case-control study of 898 cases and 3,497 controls from a cohort of children with asthma aged 5-18 years in 20042015 reported that children who were prescribed montelukast had increased odds (2 times) of experiencing a neuropsychiatric event. ${ }^{45)}$ However, 2 recent systematic reviews on this issue reported that the association between neuropsychiatric events and montelukast use was reported by studies using pharmacovigilance databases and not by observational or cohort studies. 46,47) A study assessing a cohort of 670 adults with allergic rhinitis in Spain reported that the severity of allergic rhinitis was related to a worse quality of life, sleep disturbances, depression, and anxiety. 48) One study investigated the association between montelukast and antidepressant use and reported that montelukast initiation was weakly associated with antidepressant prescription. However, the study concluded that antidepressant use, not montelukast use, may be correlated with asthma severity. ${ }^{49)}$ A study using an animal allergic rhinitis model reported that allergic rhinitis was associated with the induction of an inflammatory response in the hippocampus and that it may trigger associated neuropsychiatric events. ${ }^{50)}$ These findings do not guarantee the safety of montelukast; therefore, clinicians should consider the benefits and risks of montelukast before prescribing it.

\section{Conclusion}

The efficacy of montelukast for pediatric asthma is inferior to that of ICSs. Nonetheless, montelukast has several advantages. First, patients using ICS must use the correct inhalation technique, whereas no special skills are required to administer montelukast. Second, both patients and prescribing physicians prefer to use a drug that is administered only once a day. Third, there is no impact on growth, unlike the use of ICSs, which can potentially impair a child's growth. ${ }^{51)}$

Montelukast maintenance therapy is primarily recommended for asthmatic children who experience symptoms more than once a month but less than once a week and is recommended as an alternative method for children with step 2 asthma.

Serum EDN can be used as a biomarker to monitor the effectiv. eness of pediatric asthma treatment. We recommend starting maintenance therapy with montelukast when the EDN level is $\geq 53 \mathrm{ng} / \mathrm{mL}$ and stopping when the EDN level decreases to $<45$ $\mathrm{ng} / \mathrm{mL}$. However, additional studies are needed to determine the validity of these recommendations.

\section{Conflicts of interest}

No potential conflict of interest relevant to this article was reported.

See the commentary "Should we prescribe montelukast to allergic pediatric patients?" via https://doi.org/10.3345/cep.2019. 01662.

\section{References}

1. Harkavy J. Spasm-producing substance in the sputum of patients with bronchial asthma Arch Intern Med 1930;45:641-6.

2. Feldberg W, Kellaway CH. Liberation of histamine and formation of lysocithin-like substances by cobra venom. J Physiol 1938;94:187-226.

3. Murphy RC, Hammarström S, Samuelsson B. Leukotriene C: a slowreacting substance from murine mastocytoma cells. Proc Natl Acad Sci US A 1979;76:4275-9.

4. Dahlén SE, Hedqvist P, Hammarström S, Samuelsson B. Leukotrienes are potent constrictors of human bronchi. Nature 1980;288:484-6.

5. Dahlén SE, Hansson G, Hedqvist P, Björck T, Granström E, Dahlén B. Allergen challenge of lung tissue from asthmatics elicits bronchial contraction that correlates with the release of leukotrienes C4, D4, and E4. Proc Natl Acad Sci US A 1983;80:1712-6.

6. Smith LJ, Greenberger PA, Patterson R, Krell RD, Bernstein PR. The effect of inhaled leukotriene D4 in humans. Am Rev Respir Dis 1985;131:36872.

7. Haberal I, Corey JP. The role of leukotrienes in nasal allergy. Otolaryngol Head Neck Surg 2003;129:274-9.

8. Dahlén SE, Björk J, Hedqvist P, Arfors KE, Hammarström S, Lindgren JA, et al. Leukotrienes promote plasma leakage and leukocyte adhesion in postcapillary venules: in vivo effects with relevance to the acute inflammatory response. Proc Natl Acad Sci US A 1981;78:3887-91.

9. Marom Z, Shelhamer JH, Bach MK, Morton DR, Kaliner M. Slowreacting substances, leukotrienes $\mathrm{C} 4$ and D4, increase the release of mucus from human airways in vitro. Am Rev Respir Dis 1982;126:449-51.

10. Bisgaard H, Pedersen M. SRS-A leukotrienes decrease the activity of human respiratory cilia. Clin Allergy 1987;17:95-103.

11. Hay DW, Torphy TJ, Undem BJ. Cysteinyl leukotrienes in asthma: old mediators up to new tricks. Trends Pharmacol Sci 1995;16:304-9.

12. Choi BS, Sohn MH, Kim KE. The role of leukotriene modifier in pediatric allergic disease. Allergy Asthma Respir Dis 2015;3:255-60.

13. Okunishi K, Peters-Golden M. Leukotrienes and airway inflammation. Biochim Biophys Acta 2011;1810:1096-102.

14. Evans JF. Cysteinyl leukotriene receptors. Prostaglandins Other Lipid Mediat 2002;68-69:587-97.

15. Lynch KR, O'Neill GP, Liu Q, Im DS, Sawyer N, Metters KM, et al. Characterization of the human cysteinyl leukotriene CysLT1 receptor. Nature 1999;399:789-93.

16. Global Initiative for Asthma. Global strategy for asthma management and prevention (2018 update) [Internet]. Fantana (WI): Global Initiative for Asthma; 2018 [cited 2019 Mar 15]. Available from: http://ginasthma.org. 17. Larenas Linnemann DE, Fernández Vega M, Luna Pech JA, Villaverde 
Rosas J, Ortega Martell JA, Del Río Navarro BE, et al. Pediatric asthma treatment: what to do when international guideline recommendations do not agree. Ann Allergy Asthma Immunol 2018;121:7-13.e4.

18. Chauhan BF, Ducharme FM. Anti-leukotriene agents compared to inhaled corticosteroids in the management of recurrent and/or chronic asthma in adults and children. Cochrane Database Syst Rev 2012;(5): CD002314.

19. Castro-Rodriguez JA, Rodriguez-Martinez CE, Ducharme FM. Daily inhaled corticosteroids or montelukast for preschoolers with asthma or recurrent wheezing: a systematic review. Pediatr Pulmonol 2018;53: 1670-7.

20. Ducharme FM, Noya FJ, Allen-Ramey FC, Maiese EM, Gingras J, Blais L. Clinical effectiveness of inhaled corticosteroids versus montelukast in children with asthma: prescription patterns and patient adherence as key factors. Curr Med Res Opin 2012;28:111-9.

21. Sol IS, Kim YH, Kim SY, Choi SH, Kim JD, Kim BO, et al. Prescription patterns and burden of pediatric asthma in Korea. Allergy Asthma Immunol Res 2019;11:280-90.

22. Kim CK, Callaway Z, Choi J, Kim HB, Kwon EM, Chang YS, et al. Multicenter adherence study of asthma medication for children in Korea. Allergy Asthma Immunol Res 2019;11:222-30.

23. Szefler SJ, Phillips BR, Martinez FD, Chinchilli VM, Lemanske RF, Strunk $\mathrm{RC}$, et al. Characterization of within-subject responses to fluticasone and montelukast in childhood asthma. J Allergy Clin Immunol 2005; $115: 233-42$.

24. Bacharier LB, Boner A, Carlsen KH, Eigenmann PA, Frischer T, Götz $\mathrm{M}$, et al. Diagnosis and treatment of asthma in childhood: a PRACTALL consensus report. Allergy 2008;63:5-34.

25. Taussig LM, Wright AL, Holberg CJ, Halonen M, Morgan WJ, Martinez FD. Tucson Children's Respiratory Study: 1980 to present. J Allergy Clin Immunol 2003;111:661-75; quiz 676.

26. Brand PL, Baraldi E, Bisgaard H, Boner AL, Castro-Rodriguez JA, Custovic A, et al. Definition, assessment and treatment of wheezing disorders in preschool children: an evidence-based approach. Eur Respir J 2008;32:1096-110.

27. Peng WS, Chen X, Yang XY, Liu EM. Systematic review of montelukast's efficacy for preventing post-bronchiolitis wheezing. Pediatr Allergy Im. munol 2014;25:143-50.

28. Kim CK, Choi J, Kim HB, Callaway Z, Shin BM, Kim JT, et al. A randomized intervention of montelukast for post-bronchiolitis: effect on eosinophil degranulation. J Pediatr 2010;156:749-54.

29. Brodlie M, Gupta A, Rodriguez-Martinez CE, Castro-Rodriguez JA, Ducharme FM, McKean MC. Leukotriene receptor antagonists as maintenance and intermittent therapy for episodic viral wheeze in children. Cochrane Database Syst Rev 2015;(10):CD008202.

30. Brodlie M, Gupta A, Rodriguez-Martinez CE, Castro-Rodriguez JA, Ducharme FM, McKean MC. Leukotriene receptor antagonists as maintenance or intermittent treatment in pre-school children with episodic viral wheeze. Paediatr Respir Rev 2016;17:57-9.

31. Brand PL, Caudri D, Eber E, Gaillard EA, Garcia-Marcos L, Hedlin G, et al. Classification and pharmacological treatment of preschool wheezing: changes since 2008. Eur Respir J 2014;43:1172-7.

32. Hussein HR, Gupta A, Broughton S, Ruiz G, Brathwaite N, Bossley CJ. A meta-analysis of montelukast for recurrent wheeze in preschool children. Eur J Pediatr 2017;176:963-9.

33. Kim CK. Eosinophil-derived neurotoxin: a novel biomarker for diagnosis and monitoring of asthma. Korean J Pediatr 2013;56:8-12.

34. Lee YJ, Fujisawa T, Kim CK. Biomarkers for recurrent wheezing and asthma in preschool children. Allergy Asthma Immunol Res 2019;11:1628.
35. Kim CK, Callaway Z, Park JS, Kwon E. Utility of serum eosinophilderived neurotoxin (EDN) measurement by ELISA in young children with asthma. Allergol Int 2017;66:70-74.

36. Kim CK, Callaway Z, Fletcher R, Koh YY. Eosinophil-derived neurotoxin in childhood asthma: correlation with disease severity. J Asthma 2010; 47:568-73.

37. Kim CK, Callaway Z, Park JS, Nishimori H, Ogino T, Nagao M, et al. Montelukast reduces serum levels of eosinophil-derived neurotoxin in preschool asthma. Allergy Asthma Immunol Res 2018;10:686-97.

38. Nagao M, Ikeda M, Fukuda N, Habukawa C, Kitamura T, Katsunuma T, et al. Early control treatment with montelukast in preschool children with asthma: a randomized controlled trial. Allergol Int 2018;67:72-8.

39. Kim MK, Lee SY, Park HS, Yoon HJ, Kim SH, Cho YJ, et al. A randomized, multicenter, double-blind, phase iii study to evaluate the efficacy on allergic rhinitis and safety of a combination therapy of montelukast and levocetirizine in patients with asthma and allergic rhinitis. Clin Ther 2018;40:1096-107.e1.

40. Bisgaard H, Skoner D, Boza ML, Tozzi CA, Newcomb K, Reiss TF, et al. Safety and tolerability of montelukast in placebo-controlled pediatric studies and their open-label extensions. Pediatr Pulmonol 2009;44:56879.

41. Hauser T, Mahr A, Metzler C, Coste J, Sommerstein R, Gross WL, et al. The leucotriene receptor antagonist montelukast and the risk of ChurgStrauss syndrome: a case-crossover study. Thorax 2008;63:677-82.

42. Calapai G, Casciaro M, Miroddi M, Calapai F, Navarra M, Gangemi S. Montelukast-induced adverse drug reactions: a review of case reports in the literature. Pharmacology 2014;94:60-70.

43. Aldea Perona A, García-Sáiz M, Sanz Álvarez E. Psychiatric disorders and montelukast in children: a disproportionality analysis of the VigiBase(®). Drug Saf 2016;39:69-78.

44. Haarman MG, van Hunsel F, de Vries TW. Adverse drug reactions of montelukast in children and adults. Pharmacol Res Perspect 2017;5: e00341.

45. Glockler-Lauf SD, Finkelstein Y, Zhu J, Feldman LY, To T. Montelukast and neuropsychiatric events in children with asthma: a nested casecontrol study. J Pediatr 2019;209:176-82.e4.

46. Khalid F, Aftab A, Khatri S. The association between leukotrienemodifying agents and suicidality: a review of literature. Psychosomatics 2018;59:19-27.

47. Law SW, Wong AY, Anand S, Wong IC, Chan EW. Neuropsychiatric events associated with leukotriene-modifying agents: a systematic review. Drug Saf 2018;41:253-65.

48. Muñoz-Cano R, Ribó P, Araujo G, Giralt E, Sanchez-Lopez J, Valero A. Severity of allergic rhinitis impacts sleep and anxiety: results from a large Spanish cohort. Clin Transl Allergy 2018;8:23.

49. Winkel JS, Damkier P, Hallas J, Henriksen DP. Treatment with montelukast and antidepressive medication-a symmetry analysis. Pharmacoepidemiol Drug Saf 2018;27:1409-15.

50. Yang S, Wu J, Zhang Q, Li X, Liu D, Zeng B, et al. Allergic rhinitis in rats is associated with an inflammatory response of the hippocampus. Behav Neurol 2018;2018:8750464.

51. Zhang L, Lasmar LB, Castro-Rodriguez JA. The impact of asthma and its treatment on growth: an evidence-based review. J Pediatr (Rio J) 2019;95 Suppl 1:10-22.

How to cite this article: Lee YJ, Kim CK. Montelukast use over the past 20 years: monitoring of its effects and safety issues. Clin Exp Pediatr 2020;63:376-81. https://doi.org/10.3345/ cep.2019.00325 